EPiC Series in Engineering
Volume 3, 2018, Pages 372-380
HIC 2018. 13th International
Conference on Hydroinformatics

\title{
Impacts of Regional Climate Model Spatial Resolution on Summer Flood Simulation
}

\author{
Mariana Castaneda-Gonzalez ${ }^{1}$, Annie Poulin ${ }^{1}$, Rabindranarth Romero- \\ Lopez $^{2}$, Richard Arsenault ${ }^{1}$, François Brissette ${ }^{1}$, Diane Chaumont ${ }^{3}$ \\ and Dominique Paquin ${ }^{3}$ \\ ${ }^{1}$ École de technologie supérieure, Montreal, Canada \\ mariana.castaneda-gonzalez.1@ens.etsmtl.ca, \\ annie.poulin@etsmtl.ca, richard.arsenaulteetsmtl.ca, \\ francois.brissettedetsmtl.ca \\ ${ }^{2}$ Universidad Veracruzana, Xalapa, Mexico \\ rabromero@uv.mx \\ ${ }^{3}$ Consortium Ouranos, Montreal, Canada \\ chaumont.diane@ouranos.ca, paquin.dominique@ouranos.ca
}

\begin{abstract}
This study aims to evaluate the impact of the Canadian Regional Climate Model's (CRCM) spatial resolution on summer floods simulation. Four different climate simulations issued from the fourth version of the CRCM (two driven by the Canadian General Circulation Model (CGCM) and two driven by the ERA40c reanalysis) are employed. One simulation at $45 \mathrm{~km}$ resolution and another one at $15 \mathrm{~km}$ resolution for each driver were compared on a daily time-step for the 1960-1990 period. These four simulations are used as inputs for two hydrological models of varying complexity (HSAMI and MOHYSE). Each model is calibrated using three different objective functions based on the Kling-Gupta Efficiency criterion (KGE) to target floods. Two seasonal indices are used to evaluate the CRCM outputs: bias (temperature) and relative bias (precipitation). For the streamflow simulations analysis, the seasonal values of KGE and relative bias are used. The results show an impact of spatial resolution on climate model outputs, on streamflow simulation and flood indicators in the hydrological models. However, other elements such as climate model driver and domain size can influence the results, highlighting the need for further research to assess the impact of spatial resolution on summer floods.
\end{abstract}




\section{Introduction}

Over the course of the years, catastrophic hydrological events such as droughts and floods have occurred around the world causing intense social and economic impacts. Furthermore, it is anticipated that climate change will modify the hydrological regimes in many world regions. As a result, the number of studies evaluating the potential impact of climate change on extreme hydrological events has increased dramatically. Hydrological modelling and streamflow forecasting thus play an important role in the global and regional economy and in many aspects of social development (Grey \& Sadoff, 2007)

The climate change impacts on hydrology are usually evaluated using the climate model outputs as inputs for the hydrological models. During the last decades, numerous global climate models (GCMs) have been developed and downscaled with higher-resolution regional climate models (RCMs) that can improve the representation of climate variables such as precipitation (Teutschbein \& Seibert, 2010). Therefore, researchers have thrived to improve climate model resolution as it is thought that the finer scales will allow for a better representation of the hydrological processes for studies at the catchment scale (Hawkins et al., 2013; Lee \& Bae, 2016; Teutschbein \& Seibert, 2010).

The increase in spatial resolution also increases the climate model and hydrological model simulation times, which raises the need to evaluate how increasing resolution in climate modelling impacts the hydrological streamflow simulations. In other words, it is necessary to analyse the effects of the higher climate model resolution on the simulation of hydrological extremes such as floods. Thus, to address this issue, the main objective is to analyse the spatial resolution impact of the fourth version of the Canadian Regional Climate Model (CRCM) on the hydrological modelling of rainfalldriven floods in central and southern Quebec.

\section{Data and methodology}

The main parts of the methodology are (1) evaluating the climate outputs (temperature and precipitation), (2) performing the hydrological modelling using the climate datasets from differentresolution CRCM simulations, and (3) computing the summer-fall return periods by a flood frequency analysis using the Gumbel distribution (see Figure 1). This methodology is applied on 50 watersheds in central and southern Quebec over the reference period.

\subsection{Climate datasets}

Four climate simulations issued from the Canadian Regional Climate Model (CRCM) version 4 (Caya \& Laprise, 1999) were used to simulate summer-fall floods (listed in Table1).

\begin{tabular}{llll}
\hline Acronym* & Pilot & Domain & Resolution \\
\hline $15_{\mathrm{km}}(\text { CGCM })_{\mathrm{QC}}$ & CGCM3.1v2 & Quebec & $15 \mathrm{~km}$ \\
$45_{\mathrm{km}}(\text { CGCM })_{\mathrm{AMNO}}$ & CGCM3.1v2 & North America & $45 \mathrm{~km}$ \\
$15_{\mathrm{km}}(\text { ERA40c })_{\mathrm{QC}}$ & ERA40C & Quebec & $15 \mathrm{~km}$ \\
$45_{\mathrm{km}}(\text { ERA40c })_{\text {AMNO }}$ & ERA40C & North America & $45 \mathrm{~km}$ \\
\hline
\end{tabular}

*The acronym stands for: Resolution (Driver) Domain.

Table 1 Description of the climate datasets 


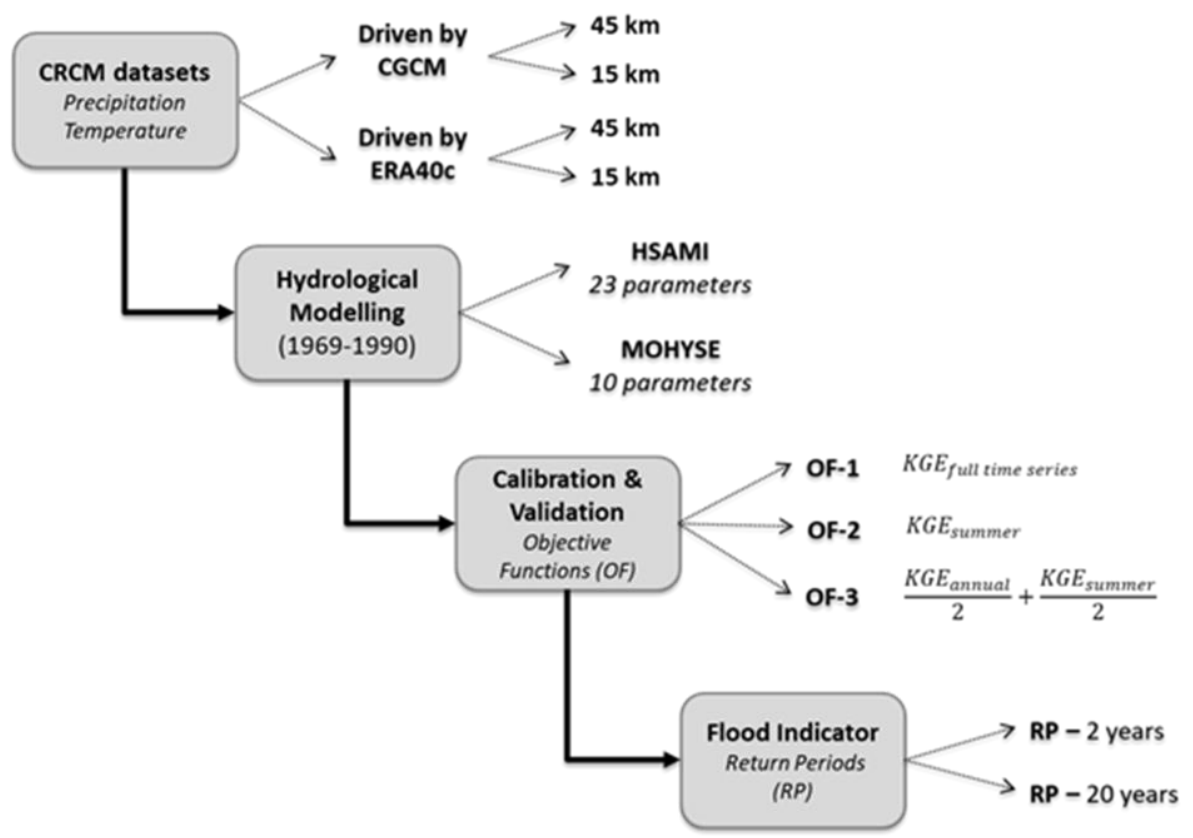

Figure 1 Schematic representation of the methodology.

\subsection{Hydrological modelling}

The hydrological simulations were carried out by two different hydrological models of varying complexity. HSAMI (Fortin, 2000) is a lumped, conceptual, rainfall-runoff model with 23 parameters and MOHYSE (Fortin \& Turcotte, 2006) is a simplified, lumped, conceptual model with 10 parameters. For the calibration and validation of the hydrological modelling, the KGE (Gupta et al., 2009) (equations (1) - (3)) is the base of the three different objective functions used in this study (see Figure 1).

$$
\begin{aligned}
& K G E=1-\sqrt{(r-1)^{2}+(\alpha-1)^{2}+(\beta-1)^{2}} \\
& \alpha=\frac{C V_{s}}{C V_{o}}=\frac{\sigma_{s} / \mu_{s}}{\sigma_{o} / \mu_{o}} \\
& \beta=\frac{\mu_{s}}{\mu_{o}}
\end{aligned}
$$

Where $r$ is Pearson's correlation coefficient, $\alpha$ is the variability error, and $\beta$ represents the bias error. The $\mu$ represents the mean streamflow, $\mathrm{CV}$ is the variation coefficient and $\sigma$ is the standard deviation of the observed (" $o$ ") and simulated (" $s$ ") streamflows. This KGE criterion measures the goodness of fit between two datasets ranging from -Infinite to 1, where a value of 1 indicates a perfect fit between the datasets, a value of 0 means a good fit on average values and negative values indicates worse fitting than using the mean as a predictor. The KGE criterion has been shown to 
overcome the problems related to the use of functions based on the mean squared error (e.g. runoff peaks and variability underestimation) such as the Nash-Sutcliffe efficiency metric, one of the most commonly used objective functions in hydrological model calibration (Gupta et al., 2009; Nash \& Sutcliffe, 1970). Along with it, the KGE increasing popularity in the literature (Beck et al., 2016; Huang et al., 2016; Oyerinde et al., 2017; Thirel et al., 2015), warrants its use in this study.

\subsection{Simulations comparison criteria}

For the climate outputs analysis, two metrics were used to evaluate the seasonal impact of spatial resolution: bias (temperature) and relative bias (precipitation). For the streamflow, the KGE criterion between streamflow simulations and the relative bias between return periods are used. All comparisons were performed by comparing the differences between the $15 \mathrm{~km}$ and $45 \mathrm{~km}$ resolutions (presented as $15 \mathrm{~km} / 45 \mathrm{~km}$ ), where the $45 \mathrm{~km}$ simulation is always used as the reference dataset for climate and streamflow inter comparisons.

\section{Results}

\subsection{Climate simulations}

Figures 2 and 3 show the temperature seasonal biases $\left({ }^{\circ} \mathrm{C}\right)$ and the precipitation seasonal relative biases (\%) between the simulations at different resolutions, respectively. The figures show the obtained biases for the summer (June, July and August) and fall (September, October and November) seasons over the province of Quebec with the fifty watersheds highlighted in black.

On the comparisons of temperature simulations driven by CGCM (upper panel a in Figure 2) a consistent hot bias is observed during the fall ( $\mathrm{SON}$ ). More variability is observed during the summer (JJA) with a bias varying between +2 and -2 degrees Celsius. On the other hand, the comparisons of the ERA40c-driven simulations (lower panel b) show similar trends in the summer and fall seasons. A general cold bias is observed with some hot spots in the center and southern regions of the province. This is true for both seasons with a slightly hotter bias observed in the center of the province during the summer months.

For precipitation, seasonal relative bias comparisons between the $15 \mathrm{~km}$ and $45 \mathrm{~km}$ simulations show a consistent wet bias over the entire province for both drivers (see Figure 3). However, on the CGCM-driven simulations (upper panel a) the wet relative biases are smaller than the relative biases on the ERA40c-driven simulations. Also, differences are observed during the fall months of the CGCM-driven simulations. Dryer relative biases are observed on the southeast side of the province, where the largest studied watersheds are located. The ERA40c-driven simulations comparisons (lower panel b) show larger wet biases (up to $50 \%$ ) during both seasons.

\subsection{Hydrological modelling}

Figure 4 displays the distributions of the Kling-Gupta Efficiency values to evaluate the streamflow simulations against observed streamflows over the full time series (left column) and the during the summer-fall months (right column). The two hydrological models, MOHYSE and HSAMI, present

good performance over the fifty watersheds with median KGE values ranging from 0.65 to 0.9 for both calibration and validation periods, and the different objective functions (OF). 
Impacts of Regional Climate Model Spatial Resolution on Summer ... M. Castaneda-Gonzalez et al.

a)
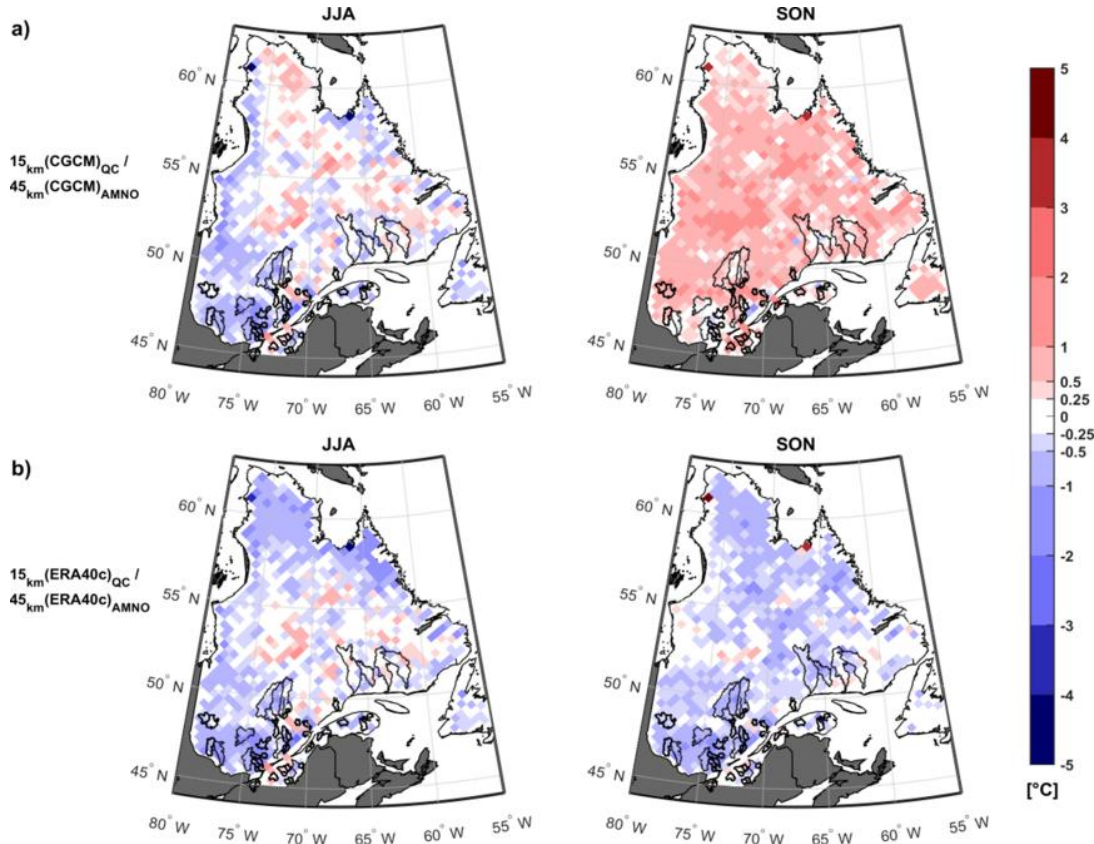

Figure 2 Temperature seasonal bias $\left({ }^{\circ} \mathrm{C}\right)$ during the summer $(\mathrm{JJA})$ and fall (SON) seasons for the 19611990 period. The upper panels (a) show the comparisons for the datasets driven by CGCM and the lower panels (b) for the datasets driven by ERA40c
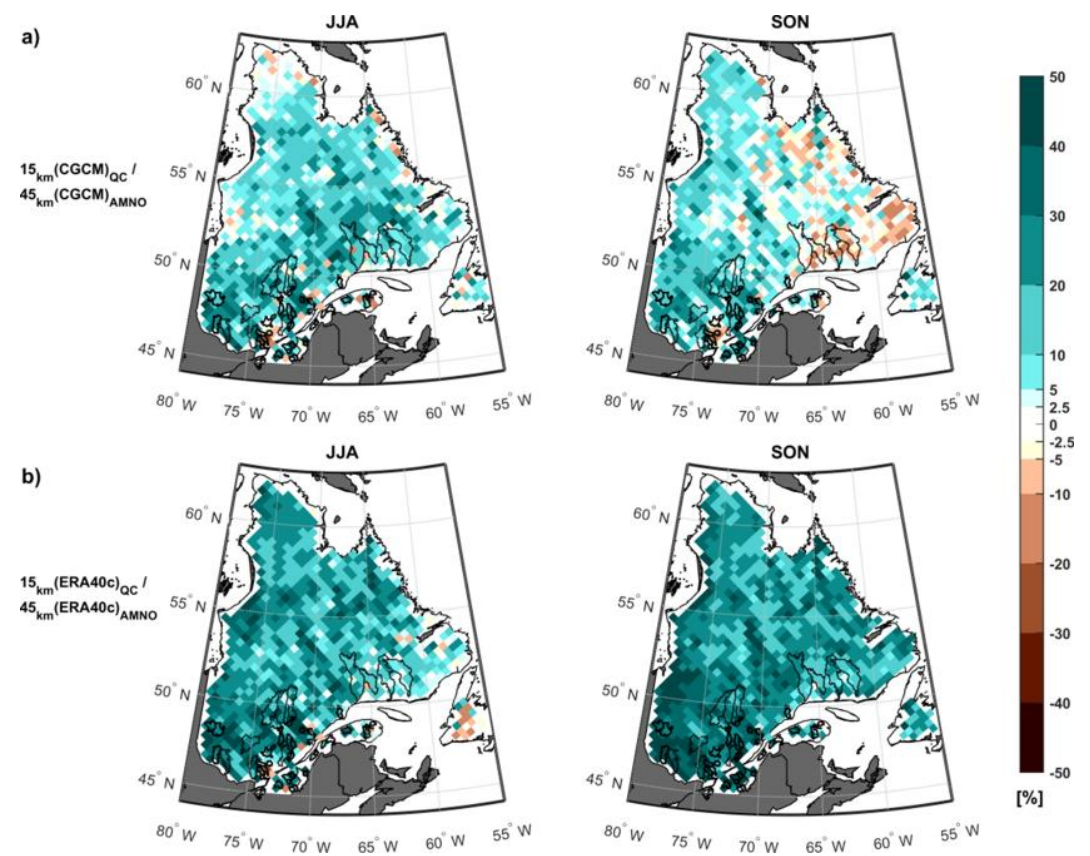

Figure 3 Precipitation seasonal relative bias (\%) for the summer (JJA) and fall (SON) seasons for the 1961-1990 period. The upper panels (a) show the comparisons for the datasets driven by CGCM and the lower panels (b) for the datasets driven by ERA40c 
a)

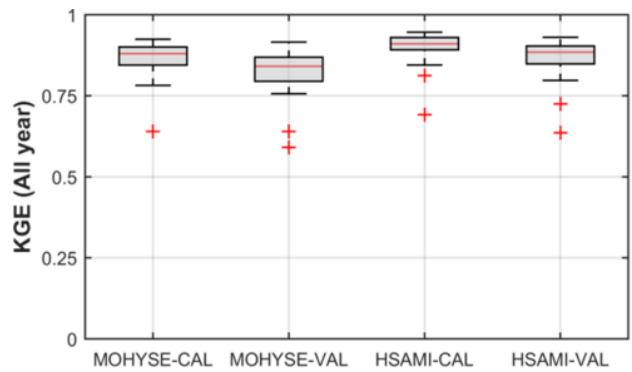

b)

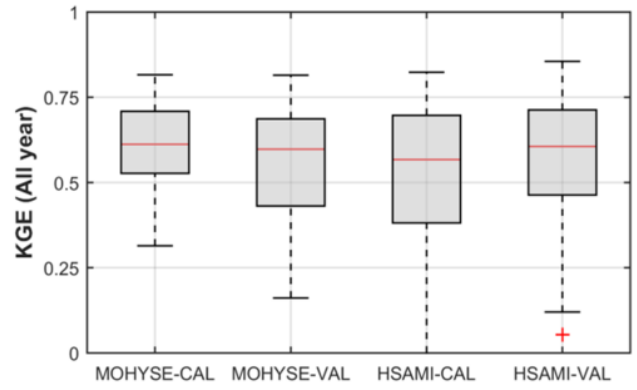

c)

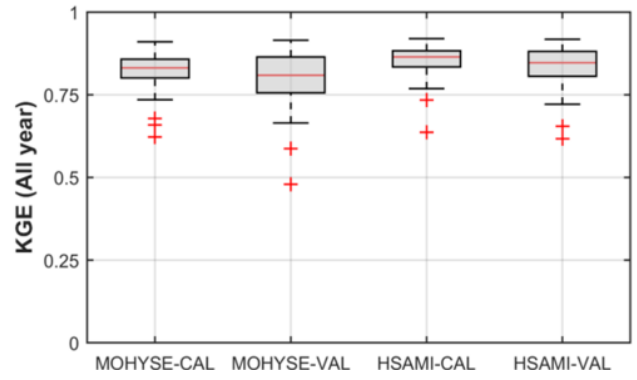

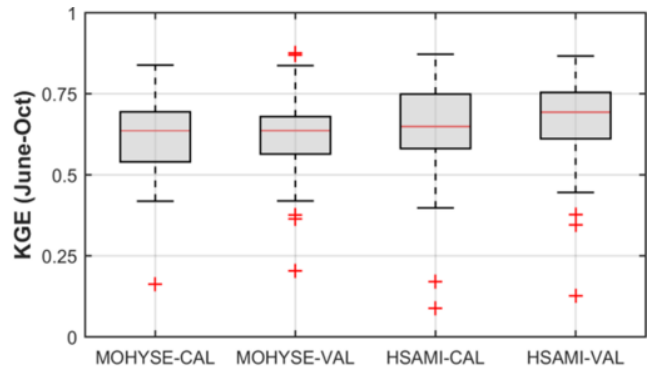
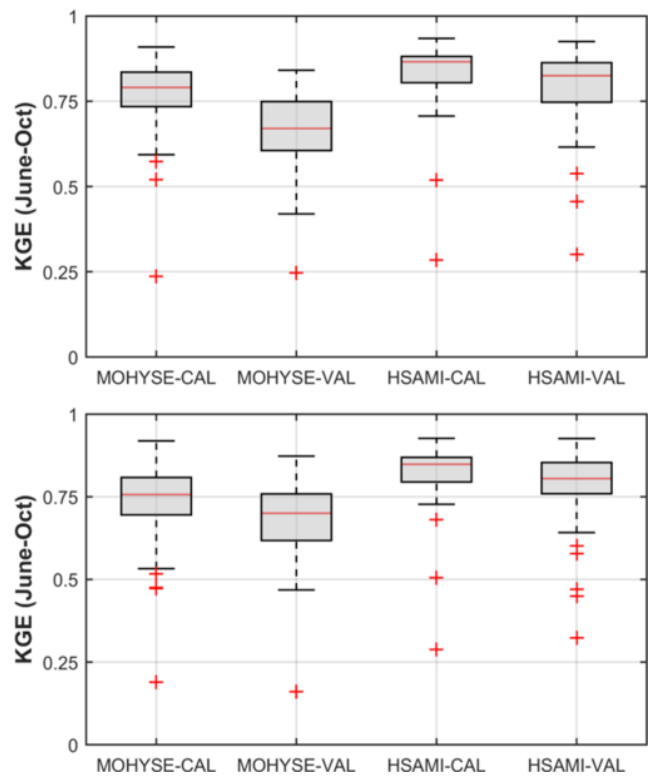

Figure 4 KGE values on the calibration and validation years. Panel a) presents the OF-1, panel b) presents the OF-2 and panel c) presents the OF-3. KGE values for the entire year (left panel) and June to October (right panel) are shown for both models

However, during the summer-fall months (right column), both models show difficulties in the streamflow simulations. More outliers and median KGE values close to 0.6 are observed. For OF-2 (b), the hydrological models perform better during June to October. Yet, both hydrological models present a decrease in the median KGE values over the full time series evaluations. For the third calibration approach (c), similar distributions are observed over the full time series and the summerfall months with slightly better median values in the full time series evaluations (left column).

\subsection{Streamflow simulations driven by CRCM4}

Figure 5 shows the seasonal comparisons of streamflows simulated with climate data at $15 \mathrm{~km}$ and $45 \mathrm{~km}$ resolutions (using the $45 \mathrm{~km}$ as the reference dataset) by using the KGE criterion for the three objective functions (OF) presented on panels $\mathrm{a}, \mathrm{b}$ and $\mathrm{c}$.

The boxplots show the difference between the streamflows simulated with $15 \mathrm{~km}$ and $45 \mathrm{~km}$ resolutions for each watershed and both drivers. Larger differences are observed between simulations driven by the ERA40c (light blue) than between simulations driven by the CGCM (dark blue). These differences are observed for all seasons, with the largest differences observed during the summer and 
fall months (JJA and SON). This tendency is observed for both hydrological models and for the three calibration approaches.
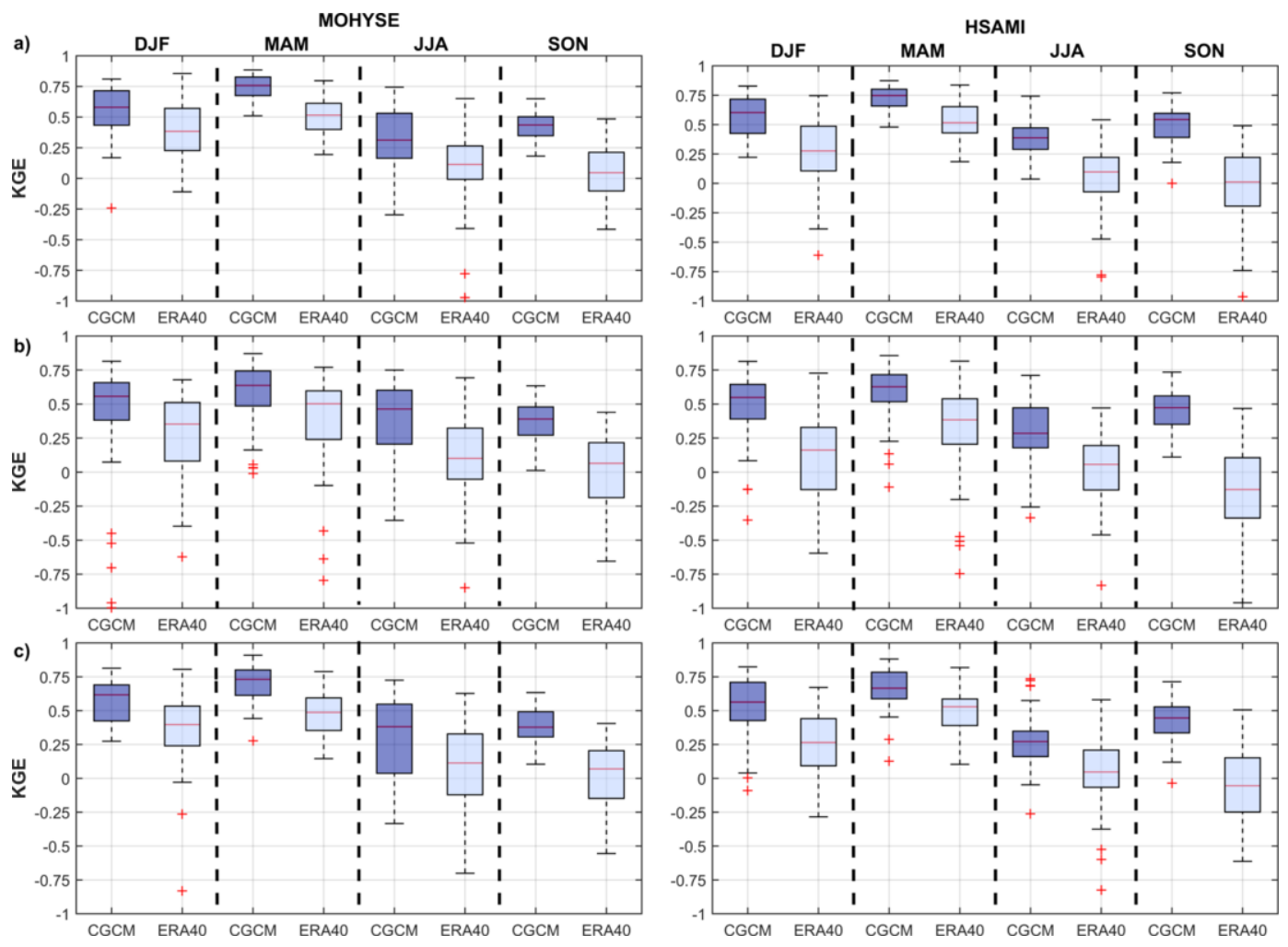

Figure 5 Seasonal KGE values of the comparisons between streamflows generated with climate outputs at 15 $\mathrm{km}$ and $45 \mathrm{~km}$ resolutions for the four seasons. The upper panels (a) present the results obtained with OF-1, the middle panels (b) present the results obtained with OF-2 and the lower panels (c) present the results obtained with OF-3. Results are shown for both drivers, CGCM and ERA40c reanalysis

Figure 6 shows the impact of the resolution on the flood frequency indicators. Each boxplot presents the relative biases between the return periods (2-year and 20-year) estimated from the streamflow simulations at $15 \mathrm{~km}$ and the $45 \mathrm{~km}$ resolution for the different drivers and both hydrological models. The results show an increase on the relative bias with increasing return periods. This is true for both hydrological models and the three objective functions (panels a, b and c).

Overall, the model structure shows small impacts on the results. Small differences are observed between the distributions obtained with both models. Regarding the impacts of hydrological model parameterization, considerable differences are observed in the spread of distributions between the three calibration approaches. The results distributions are noticeably similar for the median values with a few differences in the spread between models. These differences are especially observed in the ERA40c comparisons. 

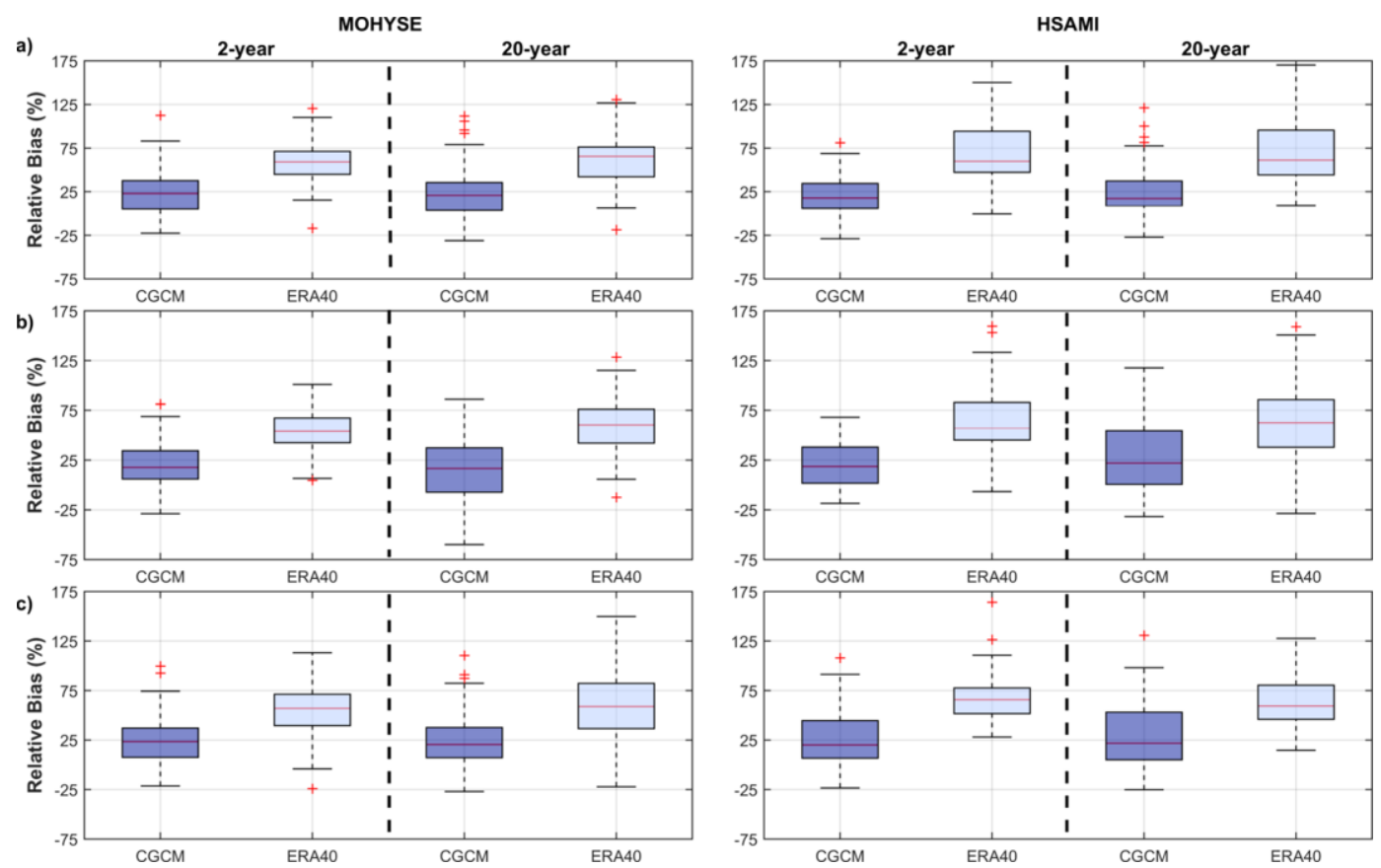

Figure 6 Summer-fall flood return periods (2 and 20 years) relative bias (\%) between streamflow simulations with different resolutions. Panel a) presents the objective function-1, b) the objective function-2 and c) presents the objective function-3

\section{Discussion and conclusion}

This research aimed to evaluate the impact of regional climate model spatial resolution on the hydrological modelling of rainfall-driven floods. The results show that the climate model resolution has an impact on temperature and precipitation simulations, which varies from summer to fall seasons. Yet, discrepancies were observed in the temperature biases estimated with the climate simulations issued from the different drivers. On the seasonal precipitation analysis, large relative biases were observed in the precipitation amounts, mainly during the summer season for both drivers.

Regarding the hydrological modelling, both hydrological models presented good performance against observations but were shown to be considerably impacted by the use of different objective functions. Nonetheless, HSAMI presented more sensitivity to the different parameter sets. This was expected as the model has more parameters than MOHYSE. Thus, HSAMI's degrees of freedom allowed the model to adapt the parameters to better simulate the hydrological processes.

On the floods analysis, the flood indicators suggested that impacts on summer-fall floods increased with increasing return periods. Although impacts linked to the climate model resolution were observed, these effects can be due to other elements involved in the climate simulations. The CRCM4 datasets have important differences. They were performed with different drivers (CGCM and ERA40c), and also different domains (Quebec-15km, and North America-45km). Therefore, the attribution of the observed differences in climate datasets, streamflow simulations and flood indicators can be due to the spatial resolution but also to the RCM domains and driver differences. For this reason, it is not possible to link the impacts directly to the spatial resolution. However, these 
results highlighted the need for further research in order to improve the confidence in our assessment of the impacts of climate model spatial resolution on rainfall-driven floods.

\section{References}

Beck, H. E., Dijk, A. I. J. M. v., Roo, A. d., Miralles, D. G., McVicar, T. R., Schellekens, J., \& Bruijnzeel, L. A. (2016). Global - scale regionalization of hydrologic model parameters. Water resources research, 52(5), 3599-3622. doi:10.1002/2015WR018247

Caya, D., \& Laprise, R. (1999). A semi-implicit semi-Lagrangian regional climate model: The Canadian RCM. Monthly Weather Review, 127(3), 341-362.

Fortin, V. (2000). Le modèle météo-apport HSAMI: historique, théorie et application. Institut de recherche d'Hydro-Québec, Varennes.

Fortin, V., \& Turcotte, R. (2006). Le modèle hydrologique MOHYSE. Note de cours pour SCA7420, Département des sciences de la terre et de l'atmosphere, Université du Québec a Montréal.

Grey, D., \& Sadoff, C. W. (2007). Sink or Swim? Water security for growth and development. Water Policy, 9(6), 545-571.

Gupta, H. V., Kling, H., Yilmaz, K. K., \& Martinez, G. F. (2009). Decomposition of the mean squared error and NSE performance criteria: Implications for improving hydrological modelling. Journal of hydrology, 377(1), 80-91.

Hawkins, E., Osborne, T. M., Ho, C. K., \& Challinor, A. J. (2013). Calibration and bias correction of climate projections for crop modelling: an idealised case study over Europe. Agricultural and forest meteorology, 170, 19-31.

Huang, S., Kumar, R., Flörke, M., Yang, T., Hundecha, Y., Kraft, P., . . Krysanova, V. (2016). Evaluation of an ensemble of regional hydrological models in 12 large-scale river basins worldwide. Climatic Change, 141(3), 381-397. doi:10.1007/s10584-016-1841-8

Lee, M.-H., \& Bae, D.-H. (2016). Uncertainty Assessment of Future High and Low Flow Projections According to Climate Downscaling and Hydrological Models. Procedia Engineering, 154(Supplement C), 617-623. doi:https://doi.org/10.1016/j.proeng.2016.07.560

Nash, J. E., \& Sutcliffe, J. V. (1970). River flow forecasting through conceptual models part I-A discussion of principles. Journal of hydrology, 10(3), 282-290.

Oyerinde, G., Hountondji, F., Lawin, A., Odofin, A., Afouda, A., \& Diekkrüger, B. (2017). Improving Hydro-Climatic Projections with Bias-Correction in Sahelian Niger Basin, West Africa. Climate, 5(1), 8.

Teutschbein, C., \& Seibert, J. (2010). Regional climate models for hydrological impact studies at the catchment scale: a review of recent modeling strategies. Geography Compass, 4(7), 834-860.

Thirel, G., Andréassian, V., Perrin, C., Audouy, J. N., Berthet, L., Edwards, P., . . Vaze, J. (2015). Hydrology under change: an evaluation protocol to investigate how hydrological models deal with changing catchments. Hydrological Sciences Journal, 60(7-8), 1184-1199. doi:10.1080/02626667.2014.967248 